\title{
To prophylactically extract or not to extract partially erupted mesio-angularly impacted lower third molars?
}

\author{
Sven Butzin ${ }^{1}$
}

\section{Key points}

Levels of third molar removal in England are exceeding levels before the introduction of guidance from the National Institute for Health and Care Excellence in 2000, with more patients attending secondary care for third molar procedures.

Partially erupted mesio-angularly impacted mandibular third molars are retained until they become symptomatic later in life, which can lead to complications involving the adjacent second molar.
As long as high-quality evidence remains unavailable, mesio-angularly impacted mandibular third molars removal should be offered to patients on the NHS.

\begin{abstract}
Introduction Prophylactic removal of mesio-angularly impacted mandibular third molars (MAIM3Ms) has been discouraged by the National Institute for Health and Care Excellence in 2000. Consequently, partially erupted MAIM3Ms are retained for longer and only extracted if complications arise. The debate whether to extract prophylactically or to monitor these teeth is ongoing.
\end{abstract}

Pathologies associated with retained partially erupted MAIM3Ms Retaining third molars long into adulthood has been associated with an increased risk of distal cervical caries and external root resorption of the second molar, periodontal disease and pericoronitis, among other pathologies. Although watchful monitoring can help to identify these pathologies, their nature often leads not only to a poor prognosis for the third molar, but also for the second molar, which then requires costly and time-consuming restorative or even prosthodontic work.

Considering prophylactic extractions While an individual risk assessment is paramount, prophylactic removal of partially erupted MAIM3Ms has been shown to have positive effects on oral health-related quality of life, to relieve the pressure on secondary care services and to be economically feasible for the NHS.

Conclusion While long-term prospective cohort studies are necessary to put an end to the ongoing controversy, patients' needs and wishes should be at the forefront of the provision of care.

\section{Introduction}

Third molars (3Ms) are colloquially referred to as wisdom teeth due to their eruption into the oral cavity at a more mature age, between 17 and 21 years. As they are the last teeth to erupt, there is often a lack of alveolar arch space distal to the second molar (2M) tooth, leading to their impaction. Due to the reduced time for mandibular growth and its cessation at a similar time to mandibular third molar (M3M) eruption in women, ${ }^{1}$ incidence rates of M3M impaction are higher in women compared to men. Although the prevalence of impacted

'School of Dentistry, University of Central Lancashire, Preston, UK

Correspondence to: Sven Butzin

Email address: s.butzin@icloud.com

Refereed Paper

Accepted 7 April 2021

https://doi.org/10.1038/s41415-021-3561-3 third molars in the United Kingdom (UK) is unknown, its prevalence is reported to range from $18-68 \%$ internationally of which around $41 \%$ are classed as mesio-angularly impacted. ${ }^{2}$ Historically, prophylactic M3M surgery was common practice, but with the introduction of the guidance from the National Institute for Health and Care Excellence (NICE) in 2000, ${ }^{3}$ this practice was discouraged and many mesioangularly impacted mandibular third molars (MAIM3Ms) are retained until they become symptomatic later in life. Still, there is ongoing controversy among dentists and oral surgeons regarding best practice despite the vast number of publications in this field.

The controversy concerning prophylactic removal of asymptomatic partially erupted MAIM3Ms is based on evaluating costs and risks of $\mathrm{M} 3 \mathrm{M}$ surgery versus watchful monitoring. It is often argued in the literature $e^{4,5}$ that the current guidance by $\mathrm{NICE}^{3}$ and the Royal College of Surgeons ${ }^{6}$ promotes reactive treatment rather than proactively minimising the risk of pathology development. Justifications for prophylactic M3M removal include the reduction of risk of distal cervical caries $(\mathrm{DCC})^{7}$ and external root resorption (ERR) ${ }^{8}$ of the $2 \mathrm{M}$, periodontal disease and pericoronitis, ${ }^{9}$ reduction of cyst and tumour development, ${ }^{10}$ reduction of mandibular fracture risk ${ }^{11}$ and the fact that the majority of M3M surgeries are merely delayed, ${ }^{12}$ which in turn increases the difficulty of surgery with age. ${ }^{13}$

\section{Pathologies associated with retained partially erupted MAIM3Ms}

One of the most common pathologies associated with partially erupted MAIM3Ms is pericoronitis, ${ }^{4}$ which is brought on by the accumulation of plaque and bacteria beneath the soft tissue operculum of the $\mathrm{M} 3 \mathrm{M}$, and sometimes also surrounding the adjacent $2 \mathrm{M}$, 
resulting in inflammation and infection. In fact, $43 \%$ of partially erupted MAIM 3 Ms have been reported to show signs of pericoronitis. ${ }^{9}$ In line with NICE guidance, ${ }^{3}$ patients are often prescribed several courses of antibiotics for recurring episodes of pericoronitis before MAIM3M removal, making pericoronitis the second most common indication for the prescription of antibiotics in dentistry, after acute dento-alveolar infections. ${ }^{14}$ The recent white paper regarding the reduction of antibiotic resistance by Thompson et al. ${ }^{15}$ has attributed the dental profession a 'vital responsibility' in combating antimicrobial resistance. Prophylactic removal of MAIM3Ms alongside antibiotic stewardship programmes could prevent the prescription of multiple courses of antibiotics for pericoronitis and hence significantly reduce the use of antibiotics in the dental setting. In addition, research has shown that patients with previous symptoms of pericoronitis benefit significantly from M3M removal in terms of improved oral healthrelated quality of life (OHRQoL) ${ }^{16}$ and that discomfort from M3M surgery is no greater than the discomfort experienced from a single multi-day episode of mild pericoronitis. ${ }^{17}$ Furthermore, serious and potentially lifethreatening complications in the form of deep space abscesses, more common in medically compromised patients, ${ }^{18}$ could be avoided.

From 2000 until 2010, the incidence of 'caries and related infections' as the main clinical diagnosis for third molar removal in secondary care had escalated by over $200 \% .{ }^{12}$ Partially erupted MAIM3Ms have been shown to be significantly associated not only with caries of the impacted molar itself but also with DCC, forming on the distal cervical root surface of the $2 \mathrm{M}$. This is a result of ineffective cleaning and food trapping as well as the formation of a deficient gingival collar at the cementoenamel junction (CEJ) of the $2 \mathrm{M}$ as a consequence of the angulation of the impacted M3M. ${ }^{7}$ Owing to the relatively slow development of caries compared to pericoronitis, DCC develops later in patients ${ }^{19}$ and has led to an increase in the mean age of M3M removal from 25 years in 2000 to 32 years in $2010 . .^{12}$ Interestingly, patients presenting with DCC typically have superior oral hygiene compared to the general population, reducing their risk of developing pericoronitis earlier in life and hence allowing time for DCC development. ${ }^{19}$ The recall interval, as set out in NICE guidance, ${ }^{20}$ for this patient group is 24 months, which is rather counter-productive for patients at increased risk of $\mathrm{DCC}^{21}$ and can lead to DCC lesions progressing deep into the tooth before being diagnosed, causing irreversible damage to the pulp which requires root canal therapy or rendering the $2 \mathrm{M}$ unrestorable. Clinically, it can be challenging to diagnose DCC as visualisation is often hindered by the partially erupted MAIM3M, and while close radiographic monitoring may detect early lesions in the $2 \mathrm{M}$, the damage to an otherwise healthy tooth cannot be undone and the tooth enters the 'restorative cycle.22

Similar to DCC, external root resorption also leads to dental hard tissue loss on the posterior surface of the $2 \mathrm{M}$ at the level of the CEJ. Unlike DCC, though, ERR is caused by odontoclastic activity as a result of continuous pressure exerted by impacted M3Ms on the cementum or outer dentinal surface of $2 \mathrm{Ms}^{8}$ Mesial inclination of M3Ms increases the contact area between the teeth, which is a major risk factor for the development of ERR. Consequently, MAIM3Ms are associated with a significantly higher frequency of ERR in 2Ms. ${ }^{8}$ ERR follows a similar pattern to DCC in that it also affects older age groups, ${ }^{23}$ but it often stays undetected for even longer periods due to the asymptomatic and aseptic pattern of destruction of ERR up to the point when it reaches the pulp. ${ }^{8}$ Early diagnosis attempts of ERR often fail due to the overlap of structures on two-dimensional radiographs masking the signs of discrete ERR lesions. ${ }^{23}$ Cone beam computed tomography (CBCT) eliminates aforementioned overlaps and can help to overcome the issue of missed diagnoses; however, its routine use is discouraged for the planning of M3M surgery, ${ }^{24}$ even though effective doses of panoramic radiography are no longer significantly lower compared to $\mathrm{CBCT} .{ }^{25}$ Once more, delayed intervention can potentiate the development of severe $2 \mathrm{M}$ pathology, potentially leading not only to the extraction of both the M3M and 2M but also to costly and complex prosthodontic work or even implant surgery, which would then again benefit from three-dimensional imaging in the form of $\mathrm{CBCT}^{26}$

As stated previously, complications surrounding M3M removal increase with age and studies have shown OHRQoL indicators to be more frequent in older patients who require $\mathrm{M} 3 \mathrm{M}$ surgery. ${ }^{27}$ Older age groups are $30 \%$ more likely to develop periodontal disease distal to the $2 \mathrm{M}$ and are twice as likely to suffer from post-operative periodontal defects after $3 \mathrm{M}$ removal. ${ }^{28}$ Moreover, the persistence of periodontal defects is also age-related. ${ }^{29}$ According to the literature, germectomy of the $\mathrm{M} 3 \mathrm{M}$, on the other hand, avoids 2M damage while showing no signs of alveolar osteitis or inferior alveolar nerve (IAN) involvement. ${ }^{27}$ Overall, the post-operative morbidity after $3 \mathrm{M}$ removal is higher with increasing age, ${ }^{13}$ indicating that early removal of partially erupted MAIM3Ms would benefit the patients.

\section{Consideration of prophylactic extractions}

The problems highlighted above are preventable and could be avoided by prophylactic extraction of partially erupted MAIM3Ms. Naturally, patients need to be informed about the risks of M3M surgery, such as permanent dysaesthesia of the IAN and the lingual nerve, reported at $0.91 \%$ and $0.37 \%$, respectively. ${ }^{30}$ In high-risk patients, where the roots of the $\mathrm{M} 3 \mathrm{M}$ are closely associated with the inferior dental canal radiographically, the risk to the IAN can be reduced by $84 \%$ when performing a coronectomy, provided that the tooth is vital, non-mobile and free from caries or root pathology. ${ }^{31}$ Besides, patients should not be medically compromised and should be fully aware of possible complications such as alveolar osteitis, infection and re-operation, among others. ${ }^{31}$ Equally, patients have the right to be informed about the consequences of non-intervention, as described above, and the benefits of prophylactic removal. The General Dental Council standards 1.4 and 1.7 clearly state that the patient's interests should be put first and that a preventative approach tailored to the patient's needs should be taken. ${ }^{32}$ Following appropriate clinical and radiographic examination, a thorough risk assessment encompassing the potential risks and benefits of retaining or prophylactically removing any partially erupted MAIM3Ms should be presented to the patient, so that they can make an informed decision and be allowed to decide the fate of their tooth.

As it stands, prophylactic removal of M3Ms is not covered by the National Health Service (NHS) since the introduction of fiscal policies following NICE guidance on third molar removal in $2000 .{ }^{12}$ In contrast to this, European countries such as Germany ${ }^{33}$ and France ${ }^{34}$ do not limit M3M removal to teeth displaying pathological changes, but rather allow for clinical decision-making on a case-by-case basis. German guidelines, for example, find that no clear distinction can be made between 
prophylactic and therapeutic M3M removal as pathology has been shown to develop and progress in the absence of clinical signs or symptoms. ${ }^{33}$ In 2017, the American Association of Oral and Maxillofacial Surgeons published a clinical paper in which they describe surgical removal to be the 'treatment of choice' for all impacted M3Ms and advocate treatment to be carried out as soon as possible. ${ }^{35}$ From a clinician's point of view, it is important to remember that while NICE advises against the extraction of pathology-free impacted M3Ms in their guidance, ${ }^{3}$ it is merely that - guidance; a tool to aid clinical decision-making.

Despite an initial decline, levels of M3M removal in most parts of the UK are exceeding levels before 2000, with more patients attending secondary care for M3M procedures, ${ }^{36}$ likely as a consequence of the reduced number of $\mathrm{M} 3 \mathrm{M}$ removals performed by general dental practitioners. This in turn has drastic financial implications, and treatment of DCC of the $2 \mathrm{M}$ alone has been estimated to cost approximately $£ 27$ million per annum. ${ }^{36}$ To date, the literature offers very limited economic evidence with regards to the comparison of prophylactic removal of impacted M3Ms versus watchful waiting. While earlier costeffectiveness analyses ${ }^{37,38}$ found no economic evidence to support prophylactic removal of impacted M3Ms, an independent economic assessment based on long-term cost-utility analyses (carried out by the Liverpool Reviews and Implementation Group ${ }^{39}$ determined an incremental cost-effectiveness ratio per quality-adjusted life year (QALY) gain of $£ 11,741$ for prophylactic removal of impacted M3Ms versus watchful waiting. Not only is this distinctly less than the $£ 20,000$ per QALY gained threshold set by NICE, ${ }^{40}$ but costs would be further reduced if the proportion of surgical removals were carried out in a primary care setting as a Band 2 treatment. ${ }^{39}$

In 2015, NICE reviewed the evidence regarding indications for the prophylactic removal of M3Ms and they are currently in the process of updating these. As conducting long-term randomised controlled trials comparing the two schools of thought (to retain or to prophylactically extract partially erupted MAIM3Ms) are unlikely to be undertaken in the near future, high-quality and long-term prospective cohort studies are required to provide the necessary evidence. Until such evidence becomes available, a 2016 Cochrane review ${ }^{41}$ concludes that in cases of asymptomatic disease-free impacted M3Ms, the decision-making process needs to be based both on operator expertise and the patients' values.

\section{Conclusion}

In summary, while NICE guidance aimed to decrease the overall number of $3 \mathrm{M}$ removals, there is mounting evidence that MAIM3M surgery is merely being delayed, bringing with it a variety of problems for the patients. These range from increased prevalence of caries and periodontal disease of the $2 \mathrm{M}$ and $\mathrm{M} 3 \mathrm{M}$ as well as increased difficulty of surgery, to decreased OHRQoL and potentially lifethreatening deep space abscess formation following M3M infection. In light of this and the limited amount of high-quality evidence available, it is this author's opinion that patients should have more autonomy and be offered prophylactic MAIM3M removal on the NHS, following consolidation of the associated risks and benefits of the treatment, thorough clinical and radiographic examination, and on a caseby-case basis taking into account relevant medical history.

Ethics declaration

The author has no conflicts of interest to declare.

Acknowledgements

I would like to express my deepest thanks to my supervisors at the University of Central Lancashire for their continued support and dedication.

\section{References}

1. Manoj Kumar S, Al-Hobeira H, Shaikh S et al. Distribution of Impacted Third Molars based on Gende and Patterns of Angulation in Dental Students of the Hai'I Region, Saudi Arabia: A Panoramic Radiographic (OPG) Study. Int J Contemp Med Res 2017; 4: 1829-1832.

2. Carter K, Worthington S. Predictors of Third Molar Impaction. J Dent Res 2016; 95: 267-276.

3. National Institute for Health and Care Excellence. Guidance on the Extraction of Wisdom Teeth: technology appraisal guidance [TA1]. 2000. Available online at https://www.nice.org.uk/guidance/ta1 (accessed March 2021).

4. McArdle L W, Andiappan M, Khan I, Jones J, McDonald F. Diseases associated with mandibular third molar teeth. Br Dent J 2018: 224: 434-440.

5. Donnell C C, Clark M V. Mandibular third molars: 'naughty' or NICE? Br Dent J 2020; 228: 506-507.

6. The Royal College of Surgeons of England. National Clinical Guidelines. 1997. Available online at https:// www.rcseng.ac.uk/-/media/files/rcs/fds/publications/ ncg97.pdf (accessed March 2021).

7. Glória J C R, Martins C C, Armond A C V , Galvão E L, dos Santos C R R, Falci S G M. Third Molar and Their Relationship with Caries on the Distal Surface of Second Molar: A Meta-analysis. J Maxillofac Oral Surg 2018; 17: 129-141.

8. Keskin Tunç S, Koc A. Evaluation of Risk Factors for External Root Resorption and Dental Caries of Second Molars Associated With Impacted Third Molars. J Maxillofac Oral Surg 2020; 78: 1467-1477.
9. Güngörmüş M. Pathologic status and changes in mandibular third molar position during orthodontic treatment. J Contemp Dent Pract 2002; 3: 13-21.

10. Stathopoulos P, Mezitis M, Kappatos C, Titsinides S, Stylogianni E. Cysts and tumors associated with impacted third molars: Is prophylactic removal justified? J Maxillofac Oral Surg 2011; 69: 405-408.

11. Giovacchini F, Paradiso D, Bensi C, Belli S, Lomurno $G$, Tullio A. Association between third molar and mandibular angle fracture: A systematic review and meta-analysis. J Craniomaxillofac Surg 2018; 46: 558-565.

12. McArdle $L W$, Renton $T$. The effects of NICE guidelines on the management of third molar teeth. Br Dent J 2012 213: E8.

13. Baensch F, Kriwalsky M S, Kleffmann W, Kunkel M. Third Molar Complications in the Elderly - A Matched-Pairs Analysis. J Oral Maxillofac Surg 2017; 75: 680-686.

14. Sturrock A, Landes D, Robson T, Bird L, Ojelabi A, Ling J. An audit of antimicrobial prescribing by dental practitioners in the north east of England and Cumbria. BMC Oral Health 2018; 18: 206

15. Thompson W, Williams D, Pulcini C, Sanderson S, Calfon $P$, Verma M. The essential role of the dental team in reducing antibiotic resistance. 2020. Available online at https://www.fdiworlddental.org/resource/fdi-whitepaper-essential-role-dental-team-reducing-antibioticresistance (accessed March 2021).

16. McGrath C, Comfort M B, Lo E C M, Luo Y. Can third molar surgery improve quality of life? A 6-month cohort study. J Oral Maxillofac Surg 2003; 61: 759-763.

17. Dodson T B. Summary of the third molar clinical trials: Report of the AAOMS task force for third molar summary. J Oral Maxillofac Surg 2012; 70: 2238-2248.

18. Thomas Indresano A, Haug R H, Hoffman M J. The third molar as a cause of deep space infections. J Oral Maxillofac Surg 1992; 50: 33-35.

19. McArdle L W, McDonald F, Jones J. Distal cervical caries in the mandibular second molar: An indication for the prophylactic removal of third molar teeth? Update. $\mathrm{Br}$ J Oral Maxillofac Surg 2014; 52: 185-189.

20. National Institute for Health and Care Excellence. Dental checks: intervals between oral health reviews - Clinical guideline [CG19]. 2004. Available online at https:// www.nice.org.uk/guidance/cg19 (accessed March 2021).

21. Toedtling V, Coulthard $P$, Thackray G. Distal caries of the second molar in the presence of a mandibular third molar - A prevention protocol. Br Dent J 2016; 221: 297-302.

22. Henry D B. The consequences of restorative cycles. Oper Dent 2009; 34: 759-760.

23. Oenning A C C, Sousa Melo S L, Groppo FC, Haiter-Neto F. Mesial inclination of impacted third molars and its propensity to stimulate external root resorption in second molars - A cone-beam computed tomographic evaluation. J Oral Maxillofac Surg 2015; 73: 379-386.

24. Matzen L H, Berkhout E. Cone beam CT imaging of the mandibular third molar: A position paper prepared by the european Academy of DentoMaxilloFacial Radiology (eADMFR). Dentomaxillofac Radiol 2019; DOI: 10.1259/ dmfr.20190039.

25. Wang A S, Stayman J W, Otake Y et al. Low-dose preview for patient-specific, task-specific technique selection in cone-beam CT. Med Phys 2014; DOI: 10.1118/1.4884039.

26. Jacobs R, Salmon B, Codari M, Hassan B, Bornstein M M Cone beam computed tomography in implant dentistry: Recommendations for clinical use. BMC Oral Health 2018; 18: 88.

27. American Association of Oral and Maxillofacial Surgeons. White Paper on Third Molar Data. 2016. Available at https://www.aaoms.org/docs/govt_ affairs/advocacy_white_papers/white_paper_third molar_data.pdf (accessed January 2021).

28. Elter J R, Offenbacher S, White Jr R P. Association of third molars with periodontal pocketing: the dental ARIC study. J Oral Maxillofac Surg 2004; 62: 73-74.

29. Faria A I, Gallas-Torreira M, López-Ratón M. Mandibular second molar periodontal healing after impacted third molar extraction in young adults. J Oral Maxillofac Surg 2012; 70: 2732-2741. 
30. Gülicher D, Gerlach K L. Incidence, risk factors and follow-up of sensation disorders after surgical wisdom tooth removal. Study of 1,106 cases. Mund Kiefer Gesichtschir 2000; 4: 99-104

31. Pitros $\mathrm{P}, \mathrm{O}^{\prime}$ Connor N, Tryfonos A, Lopes V. A systematic review of the complications of high-risk third molar removal and coronectomy: development of a decision tree model and preliminary health economic analysis to assist in treatment planning. Br J Oral Maxillofac Surg 2020; DOI: 10.1016/j.bjoms.2020.07.015.

32. General Dental Council. Standards for the Dental Team. 2013. Available online at https://www.gdc-uk.org/ information-standards-guidance/standards-and-guidance/ standards-for-the-dental-team (accessed March 2021).

33. Kunkel M. S2k-Leitlinie: Operative Entfernung von Weisheitszähnen. 2019. Available at https://www. awmf.org/uploads/tx_szleitlinien/007-003I_S2k_ Weisheitszahnentfernung_2019-08.pdf (accessed March 2021).
34. French Society of Stomatology, Maxillo-Facial Surgery and Oral Surgery (SFSCMFCO). French good practice guidelines regarding third molar removal: Indications, techniques, methods. J Stomatol Oral Maxillofac Surg 2020; 121: 418-429.

35. American Association of Oral and Maxillofacial Surgeons. The Management of Impacted Third Molar Teeth. 2017. Available at https://www.aaoms. org/docs/practice_resources/clinical_resources/ impacted_third_molars.pdf (accessed March 2021).

36. McArdle L W, Patel N, Jones J, McDonald F. The mesially impacted mandibular third molar: The incidence and consequences of distal cervical caries in the mandibular second molar. Surgeon 2018; 16: $67-73$.

37. Song F, O'Meara S, Wilson P, Golder S, Kleijnen J. The effectiveness and cost-effectiveness of prophylactic removal of wisdom teeth. Health Technol Assess 2000; 4: 1-55
38. Anjrini A A, Kruger E, Tennant M. Cost effectiveness modelling of a 'watchful monitoring strategy' for impacted third molars vs prophylactic removal under $\mathrm{GA}$ An Australian perspective. Br Dent J 2015; 219: 19-23.

39. Liverpool reviews and implementation group. Prophylactic removal of impacted third molars. 2017 Available at: https://www.nice.org.uk/guidance/ gid-tag525/documents/assessment-report (accessed March 2021)

40. National Institute for Health and Care Excellence. Guide to the methods of technology appraisal 2013 - Process and methods [PMG9]. 2013. Available at https://www. nice.org.uk/process/pmg9/chapter/the-reference-case (accessed March 2021)

41. Ghaeminia H, Perry J, Nienhuijs M E L et al. Surgical removal versus retention for the management of asymptomatic disease-free impacted wisdom teeth. Cochrane Database Syst Rev 2016; DOI: 10.1002/14651858.CD003879.pub4. 